\title{
Contribution of the Polarity of Mussel-Inspired Adhesives in the Realization of Strong Underwater Bonding
}

\author{
Youbing $\mathrm{Mu},{ }^{\dagger, \ddagger} \perp$ Xiao $\mathrm{Wu},{ }^{\dagger+, \perp}$ Danfeng Pei, ${ }^{\ddagger}$ Zelin $\mathrm{Wu},{ }^{\ddagger}$ Chen Zhang, ${ }^{\S}$ Dongshan Zhou, ${ }^{\S}$ \\ and Xiaobo Wan ${ }^{*}, \pm, \perp_{0}$
}

${ }^{\ddagger}$ The Key Laboratory of Bio-based Materials, Qingdao Institute of Bioenergy and Bioprocess Technology, Chinese Academy of Sciences, 189 Songling Road, Qingdao 266101, P. R. China

${ }^{\S}$ Department of Polymer Science and Engineering, School of Chemistry and Chemical Engineering, State Key Laboratory of Coordination Chemistry, Nanjing University, 22 Hankou Road, Nanjing, Jiangsu Province 210093, P. R. China

${ }^{\perp}$ University of Chinese Academy of Sciences, 19A Yuquan Road, Beijing 100049, P. R. China

Supporting Information

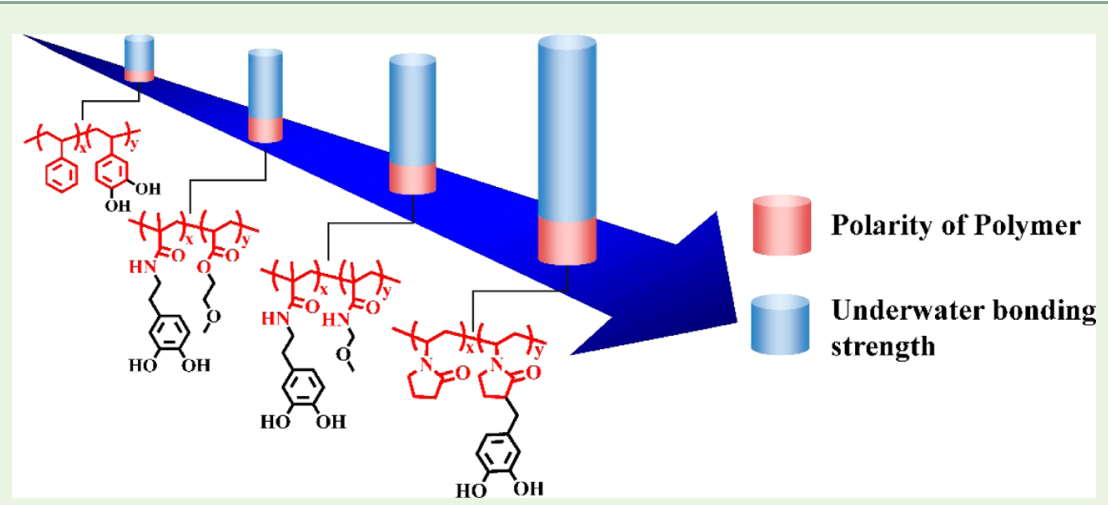

ABSTRACT: Although the role of 3,4-dihydroxyphenyl-L-alanine(DOPA)in mussel foot proteins (mfps) in the realization of underwater bonding has been widely recognized, the role of the polarity of the polymer was largely overlooked. Here, by systematically comparing the underwater bonding properties of four mussel-inspired adhesives with different amide/lactam contents but similar catechol contents and molecular weights, we came to the conclusion that the polarity of the polymers also contributes to the strong underwater bonding. With the increase in the amide/lactam contents, the polarity of the polymeric adhesive increases, which correlates to the improved underwater bonding strength. A dielectric constant is introduced to evaluate the polarity of the polymer, which may be used as a guidance for the design of mussel-inspired adhesives with even better underwater bonding properties.

KEYWORDS: underwater adhesive, poly(N-vinylpyrrolidone), backbone influence, mussel-inspired materials, dielectric

\section{INTRODUCTION}

Inspired by mussels that could attach themselves onto rocks even under turbulent marine environments, much work has been devoted to explain the underwater bonding mechanisms. ${ }^{1-6}$ It was disclosed that the strong underwater adhesion ability of mussel comes from the mussel foot proteins (mfps), a group of proteins secreted from mussels byssus rich in catecholic amino acid 3,4-dihydroxyphenyl- $L$-alanine(DOPA). Among them, mfp-3 and mfp-5 play the most important role in underwater bonding. ${ }^{7}$ Both $\mathrm{mfp}-3$ and $\mathrm{mfp}-5$ are small proteins (with molecular weight around 5.3 and $9.5 \mathrm{kDa}$, respectively). ${ }^{7}$ It is astonishing that high underwater bonding strength could be achieved via proteins with such a small molecular weight. Although the true mechanism is still quite vague at this stage, it is widely accepted that the catechol moiety on DOPA residue is vital in realizing underwater bonding, due to its strong chelation ability toward metal oxides, ${ }^{8} \mathrm{H}$-bonding formation ability and ease in undergoing oxidation/covalent cross-linking under basic conditions. ${ }^{9}$ More recently, the synergic effect of the amino group on lysine residue was also discovered, and it was found that the amino group could evict the hydrated cations from mineral surfaces, which facilitates the coordination of catechol moiety onto the surfaces. ${ }^{3}$ The influence of the hydrophobicity on the oxidation potential of DOPA hence to underwater adhesion was also discussed. ${ }^{4}$

Accompanied with the mechanistic study on the structureproperty relationship of $\mathrm{mfps}$, the design of mussel-inspired synthetic adhesives is also under fast growth, and many polymers grafted with catechol moieties were reported. ${ }^{10}$ Although both natural polymers such as chitosan $^{11}$ and

Received: September 11, 2017

Accepted: October 26, 2017

Published: October 26, 2017 

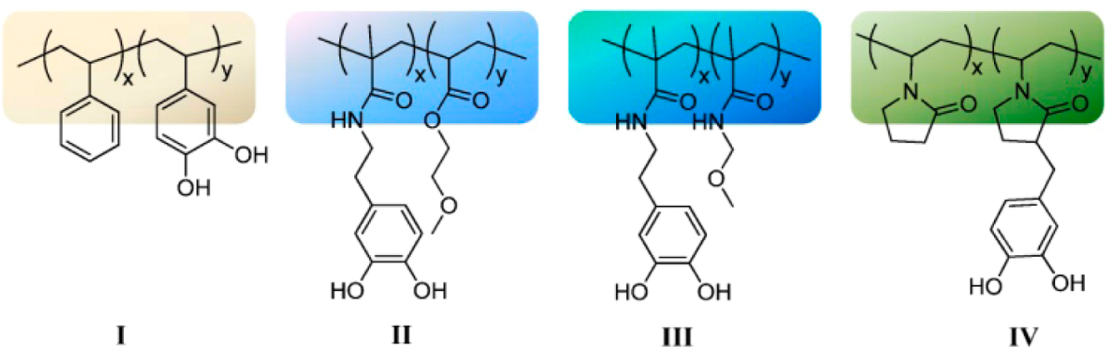

Figure 1. Structures of (I and II) reported and (III and IV) proposed mussel-inspired polymers with different backbones.

synthetic polymers such as polyurethane ${ }^{12}$ have been used as the backbone for mussel-inspired adhesives, the most commonly used ones are polyacrylates/amides ${ }^{2,13-17}$ and polystyrene. ${ }^{18-20}$ Some of them achieve quite high bonding strength at dry conditions and elevated temperature; ${ }^{15,19-21}$ however, to realize strong underwater bonding is still a challenge and is much less reported. A typical example is that polystyrene-based mussel-inspired adhesive exhibited a bonding strength up to $11 \mathrm{MPa}$ when cured at $65^{\circ} \mathrm{C}$, while its analogue (with charged amino group on the side chain) only exhibited a bonding strength around $0.4 \mathrm{MPa}$ when tested under water. ${ }^{18,20}$ Polyacrylate/amide based mussel-inspired adhesives has been applied to nanofabricated pillars and exhibits reversible underwater attach/detach capability, ${ }^{13}$ and later been used in a complex coacervate in underwater adhesion, but has not been evaluated as a single component for underwater bonding. ${ }^{16} \mathrm{Ap}$ Apparently, the much weaker underwater bonding strength compared with that at dry conditions reminds us that although the catechol moiety is the major reason for realizing underwater bonding, other factors should also be considered to further improve the underwater bonding capability of the musselinspired adhesives. More recently, one report addressed that the balanced hydrophobic/hydrophilic and cationic/anionic units in the local environment of mfps might influence the underwater adhesion. ${ }^{2}$ The acrylate-based copolymer designed via this strategy exhibited stronger underwater adhesion to mica surface than mfp-3 with a low molecular weight around $3 \mathrm{kDa}$.

We are now trying to evaluate the possible contribution of the polarity of the polymeric adhesive on the underwater adhesion ability. All mfps are connected amino acid residues via amide (peptide) bonds, regardless of whether these residues are hydrophobic or hydrophilic, polar or nonpolar, cationic or anionic. The polar amide bond and its ability to form $\mathrm{H}$ bonding may also help to enhance the interaction between mfps and surfaces, which might also be important in realizing underwater bonding. Thus, mussel-inspired adhesives with different amide/lactam contents might exhibit different underwater bonding capability. However, such a plausible contribution was not systematically compared in previous studies. Although many polymers with catechols attached to various backbones have been reported, it is hard to directly compare their underwater bonding properties and evaluate the contribution of the polarity of the polymers due to their different molecular weight, different catechol content and different test methods. We now systematically varied the polymeric structures (shown in Figure 1) and investigated their influence on underwater bonding. Four kinds of musselinspired adhesives with different structures: polystyrene-based (I), poly(acrylate-co-acrylamide)-based (II), polyacrylamidebased (III) and poly( $N$-vinylpyrrolidone) (PVP)-based (IV) with similar catechol moiety contents and molecular weights were synthesized and compared. It was found that with the increase of amide/lactam bond content in the polymer, the underwater bonding strength increased almost five times (from ca. 0.2 to $1.0 \mathrm{MPa}$ ). We found that there are trends that correlate the polarity of the polymer with the underwater adhesion ability, which might cast a light on the design of novel mussel-inspired adhesives with even stronger underwater adhesion property.

\section{EXPERIMENTAL SECTION}

Synthesis of Polymers I-IV. The syntheses of polymer I and II were carried out according to the reported work. ${ }^{13,18,22}$ Polymer III was synthesized from $\mathrm{N}$-(methoxymethyl)methacrylamide(MMA) and $N$-(3,4-dihydroxyphenethyl)methacrylamide(DMA) via azobis(isobutyronitrile) (AIBN)-initiated radical polymerization reaction. Polymer IV was obtained by the copolymerization of $\mathrm{N}$-vinyl-2pyrrolidone (VP) and 3,4-bis-(tert-butyl-dimethyl-silanyloxy)-benzyl$N$-vinyl-2-pyrrolidone (TBS-protected VP-catechol) under AIBNinitiated radical polymerization condition followed by the removal of TBS protecting group in concentrated $\mathrm{HCl}$. The chemical structures of polymers I-IV were confirmed by ${ }^{1} \mathrm{H}$ NMR spectroscopy. The corresponding ${ }^{1} \mathrm{H}$ NMR spectra and the synthetic details are shown in the Supporting Information.

Adhesion Experiments. Glass and aluminum ( $\mathrm{Al})$ were selected as the adherend for lap shear test. Glass slides $\left(10 \times 2 \mathrm{~cm}^{2}\right)$ were activated by soaking in a 2-propanol/KOH bath for $30 \mathrm{~min}$ followed by rinsing with water and ethanol and then dried before use. Al slides $\left(10 \times 2 \mathrm{~cm}^{2}\right)$ were polished, washed with water and ethanol, and dried before use. The adhesion tests both at under-seawater conditions and under dry conditions were carried out at room temperature. For under-seawater bonding, the adherends were first immersed into seawater, then a certain amount of the corresponding copolymer solution prepared in dichloromethane/methanol $(\mathrm{DCM} / \mathrm{MeOH})$ was spread on one of adherend with an area of $2 \mathrm{~cm}^{2}$ using a syringe (the relationship of dosage and concentration of polymer solution was shown in Table S1). The dosage of the polymers was fixed at around 5 $\mathrm{mg} / \mathrm{cm}^{2}$.The ends applied with the adhesives were overlapped with the other adherend, and at the same time, $20 \mu \mathrm{L}$ of $\mathrm{FeCl}_{3}$ solution in $\mathrm{MeOH}$ was added into the interlayer. Then the two ends were immediately fastened with two binder clips, and cured in seawater at room temperature for $24 \mathrm{~h}$. The molar ratio of catechol to $\mathrm{Fe}^{3+}$ was $3: 1$ according to the reported results. ${ }^{23,24}$ All the operations mentioned above were finished at under seawater. For adhesion at dry conditions, the surfaces of adherends were kept dry in all cases at room temperature. Lap shear adhesion measurements were conducted on a universal material testing system. Two soft $\mathrm{Al}$ sheets were bonded on the glass adherends using Krazy Glue before test. Adherends were pulled apart at a rate of $10 \mathrm{~mm} / \mathrm{min}$. At least five samples were measured for each test and the average value of the bonding strength was adopted, with the error bar showing the maximum deviation of the measured data. For aluminum substrates, it must be mentioned that the polymer in these experiments is actually interacting with alumina, because aluminum, when exposed to air, will rapidly develop an oxide layer to become alumina. 
Dielectric Constant Measurement. Dielectric constant measurement was carried on a Novocontrol Alpha Dielectric Spectrum Tester (Concept 80, Novocontrol Technologies GmbH \& Co, KG). The instrument was adjusted by a $100 \Omega$ standard resistance and 100pf standard capacitance before measurement. The samples of polymers I-IV were compressed into tablets (thickness: $1 \mathrm{~mm}$, diameter: 10 $\mathrm{mm}$ ) by an IR tablet presser after drying in a vacuum oven overnight. The tablets were sandwiched between two gold painting copper electrodes with $20 \mathrm{~mm}$ radius. The measurement was done at $25^{\circ} \mathrm{C}$ and under atmospheric pressure, in the frequency range from $1 \times 10^{-1}$ $\mathrm{Hz}$ to $1 \times 10^{7} \mathrm{~Hz}$. The influence of stray capacitance and boundary compensation was deducted.

Dynamic Mechanical Analysis (DMA). Dynamic mechanical analysis (DMA) of the samples was conducted on a dynamic mechanical performance tester (SDTA861e, Mettler Toledo, Switzerland). The samples for DMA tests were thin films casted from the polymer solution. Four polymers were dissolved in $\mathrm{DCM} / \mathrm{MeOH}$ to form a highly viscous solution separately. The solution was spread onto a PTFE dish and the solvent was evaporated with an air flow at $0.3 \mathrm{~m} / \mathrm{min}$ flow rate. The dried polymer films were cut into rectangle samples with $3 \mathrm{~mm}$ width and $2 \mathrm{~cm}$ length before test. However, the film obtained from the polystyrene-based biomimetic polymer was too brittle to be suitable for DMA test. During the test, the sample was heated at a heating rate of $1{ }^{\circ} \mathrm{C} / \mathrm{min}$ in a temperature range of -25 to $65{ }^{\circ} \mathrm{C}$ and its response was recorded at a frequency of $1 \mathrm{~Hz}$. DMA results of the other three polymers were obtained and compared.

SEM Measurement. After lap-shear test, the adhesion section of the glass slides was cut into $1 \mathrm{~cm} \times 1 \mathrm{~cm}$ square samples for $S E M$ test. Before test, the samples were mounted onto metallic stubs, and sputtered with gold twice in an ion-sputtering device. Measurements were carried out in a JSM-7500F Scanning Electron Microscope with an acceleration voltage of $3.0 \mathrm{kV}$. The test was in low magnification. And the work distance is $11.0 \mathrm{~mm}$.

\section{RESULTS AND DISCUSSION}

In our previous work, we had developed a mussel-inspired adhesive based on PVP backbone grafted with pendent catechol groups via click-chemistry, which exhibited excellent bonding strength up to $1.6 \mathrm{MPa}$ when applied to wet surface and cured under water. ${ }^{25}$ However, its low solubility $(\leq 0.1 \mathrm{mg} / \mathrm{mL}$ in $\mathrm{DCM} / \mathrm{MeOH}$, a binary solvent system) prohibits its direct underwater application, since the low viscosity of the formed solution makes its underwater deposition on the adherends impossible. We reasoned that the triazole group formed via click chemistry was one of the reasons accounting for its low solubility. Also, the contribution of the triazole group in underwater bonding could not be ruled out due to its strong coordination effect. Thus, to evaluate the contribution of lactam-containing repeating units in PVP in underwater adhesion, a new PVP-based mussel-inspired adhesive (Figure 1, IV) was synthesized (see the Supporting Information for synthetic details). To our delight, the solubility of polymer IV in $\mathrm{DCM} / \mathrm{MeOH}$ increased to around $1.0 \mathrm{~g} / \mathrm{mL}$, allowing the formation of a viscous solution that could be directly applied to various surfaces underwater. For comparison, several other mussel-inspired adhesives were also synthesized (polymers IIII). It should be noted that although polystyrene-based adhesive I and poly(acrylate-co-acrylamide)-based adhesive II have been synthesized by several research groups, ${ }^{13,19}$ a systematical comparison on their underwater adhesion property has not been made before. Polymer III with all amide-bondcontaining repeating units, was also synthesized to investigate the influence of the increase of amide bond content on the underwater bonding properties. For consistence, polymers IIV with very similar molecular weights (around $13.5 \mathrm{kDa}$, verified by GPC analysis) and catechol contents (20 mol \%, verified by NMR analysis (the ${ }^{1} \mathrm{H}$ NMR spectra and the calculation are shown in the Supporting Information)) were used for comparison (Table 1). Such molecular weights and

Table 1. Characterization Data of Polymers I-IV

\begin{tabular}{ccccl} 
polymer & $\begin{array}{c}\text { catechol content } \\
(\mathrm{mol} \%)\end{array}$ & $\begin{array}{c}M_{\mathrm{n}} \\
(\mathrm{kDa})\end{array}$ & PDI & \multicolumn{1}{c}{ appearance } \\
\hline polymer I & 20.5 & $13.7^{a}$ & 1.9 & powder \\
polymer II & 20.9 & 14.2 & 2.1 & viscoelastic solid \\
polymer III & 21.3 & 12.8 & 2.3 & powder \\
polymer IV & 20.0 & $13.1^{a}$ & 2.0 & powder
\end{tabular}

${ }^{a}$ The molecular weight was calculated from that of TBS-protected polymer.

catechol contents were selected based on the molecular weight of $\mathrm{mfp}-5(\sim 10 \mathrm{kDa})^{7}$ and the average content of DOPA residues in $\mathrm{mfps}(\sim 20 \mathrm{~mol} \%) .{ }^{26}$ Polymers I, III, and IV are obtained as powders, whereas polymer II is a rubberlike viscoelastic solid.

Very interestingly, although all four polymers have very similar molecular weights and catechol contents, they exhibit drastic difference in their solubility, reflecting the influence of the type of the repeating units in the polymer backbones on the polarity of the polymers. Polystyrene-based adhesive I could be easily dissolved in many common organic solvents such as acetone, tetrahydrofuran, DCM, and ethyl acetate. Ppoly(acrylate-co-acrylamide)-based adhesive II can only be dissolved in polar solvent such as acetone, chloroform, $\mathrm{MeOH}, \mathrm{N}$ methyl pyrrolidone (NMP), dimethyl sulfoxide (DMSO), and dimethyl sulfoxide (DMF). With the further increase in amide bond content, polyacrylamide-based adhesive III and PVPbased adhesive IV could only be dissolved highly polar solvents such as DMSO and DMF. A binary solvent system consisting of $\mathrm{DCM} / \mathrm{MeOH}$ with adjustable polarity, was selected to dissolve the polymers I-IV for underwater bonding tests, because the high boiling point and water-soluble solvents such as DMSO and DMF are not suitable for the solidifying and sizing of underwater adhesives. The volume ratio of $\mathrm{DCM} / \mathrm{MeOH}$ was adjusted according to the polarity of the polymers, $\left(V_{\mathrm{DCM}}: V_{\mathrm{MeOH}}=3: 1\right)$ for polystyrene-based adhesive $\mathbf{I}$, and $\left(V_{\mathrm{DCM}}: V_{\mathrm{MeOH}}=1: 1\right)$ for the other three polymers.

It should be mentioned that various techniques such as single molecular force spectroscopy (SMFS), ${ }^{27}$ atomic force microscopy (AFM) integrated with optical microscopy, ${ }^{13}$ quartz crystal microbalance, ${ }^{28,29}$ and surface force apparatus $(\mathrm{SFA})^{30}$ were used to evaluate underwater/wet adhesion properties in nanoscale. Microscale (in millimeters) reversible adhesion evaluation has also been applied. ${ }^{14}$ Although these methods provide important information at microscopic and molecular level, the lap-shear tests of the underwater bonded adherends are equally important since it provides the practical evaluation gauge for underwater adhesion. ${ }^{17,18}$ Thus, with the four polymeric adhesives in hand, we systematically tested their underwater bonding properties using the lap-shear method.

Specifically, the underwater bonding tests were conducted on two different surfaces: glass and Al foil. The substrates were cleaned before use. All the operations were finished under seawater. The adherends were placed under seawater, then a certain amount of the corresponding polymer solution in $\mathrm{DCM} / \mathrm{MeOH}$ was spread on one of adherend with an area of 2 $\mathrm{cm}^{2}$ using a syringe, as illustrated in Figure 2a. The end of the adherend applied with the adhesives was overlapped with the 
a)

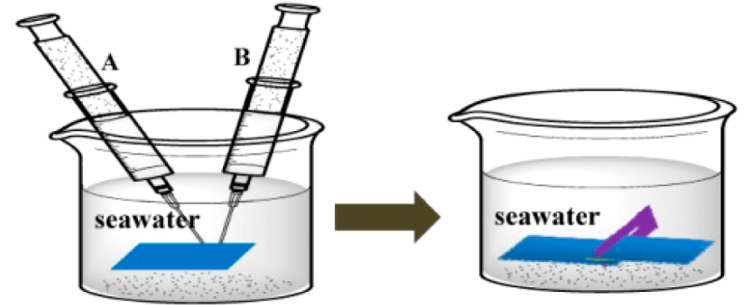

Gumming at underwater

Cross-linking in water for

$24 \mathrm{~h}$ at room temperature
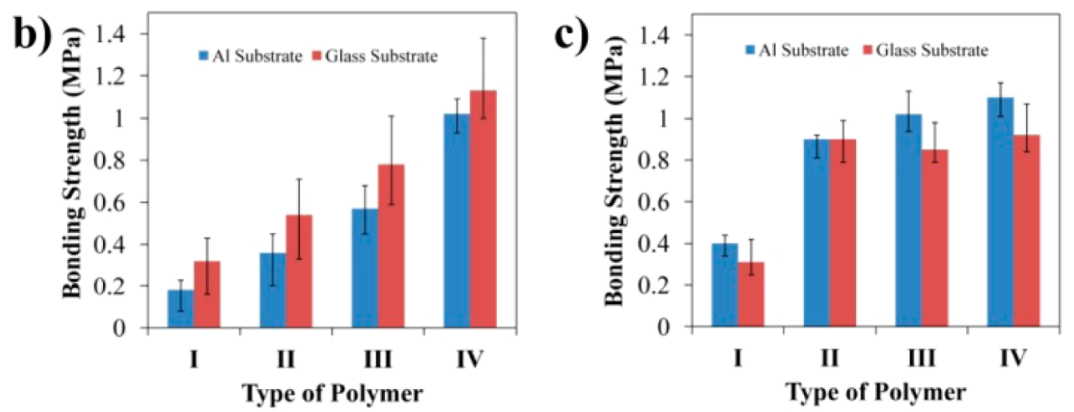

Figure 2. (a) Schematic illustration of underwater adhesion: A, solution of polymer $\mathbf{I}-\mathbf{I V}$ in DCM/MeOH, B, solution of $\mathrm{FeCl}_{3}$ in $\mathrm{MeOH}$ (b) Underwater bonding strength of polymer I-IV on glass and Al substrates, (c) Bonding strength of polymer I-IV on glass and Al substrates at dry conditions. The vertical lines on the histogram present the error bar, showing the maximum deviation of the measured data.

other adherend, subsequently a certain amount of $\mathrm{FeCl}_{3}$ solution in $\mathrm{MeOH}$ was added into the interlayer. The adherends were fastened by two binder clips and cured under seawater at room temperature for $24 \mathrm{~h}$ before tests. For comparison, the bonding strength of the four adhesives at dry conditions were also tested, using the same dosage of the adhesives and cross-linker $\left(\mathrm{FeCl}_{3}\right)$ as that for underwater tests.

The results for underwater bonding strength are shown in Figure $2 \mathrm{~b}$. Polymer I, with the nonpolar styrene repeating units, exhibits the lowest average underwater bonding strength (0.18 $\mathrm{MPa}$ ) on $\mathrm{Al}$ substrate. Polymer II, with $20 \mathrm{~mol} \%$ amidecontaining repeating units and $80 \mathrm{~mol} \%$ ester-containing repeating units, is more polar than polymer $\mathbf{I}$, and exhibits better average underwater bonding strength $(0.36 \mathrm{MPa})$ on $\mathrm{Al}$ substrate. Polymer III, with all amide-containing repeating units, is theoretically even more polar than polymer II, and boosts the average underwater bonding strength on $\mathrm{Al}$ substrate to $0.57 \mathrm{MPa}$. Polymer IV, with all lactam-containing repeating units, shows the best average underwater bonding strength of $1.02 \mathrm{MPa}$ on $\mathrm{Al}$ substrate, which is five-times stronger than that of polymer $\mathbf{I}$.

Similar trend is observed for underwater bonding on glass substrates, with $1.13 \mathrm{MPa}$ average bonding strength for polymer IV, which is almost four-times stronger than that of polymer I $(0.32 \mathrm{MPa})$. Given that the catechol contents and the molecular weights of all four polymers are very similar, we can conclude that the polymer backbone does contribute to underwater bonding strength. It is worth to mention that the above bonding process were carried out under seawater instead of under deionized (DI) water, which exhibited better bonding strength, presumably due to the complexation of the polymers with the metal ions presented in seawater and the slightly basic conditions that might accelerate the oxidation of catechol moieties. For comparison, adhesion test results under DI water are given in Figure S10, where the same bonding strength evolution trend was observed.
The comparison between the underwater bonding strength and bonding strength at dry conditions (shown in Figure 2c) is very instructive. Again, polymer I exhibits the lowest average bonding strength $(0.42 \mathrm{MPa})$ on $\mathrm{Al}$ substrate, but almost two times stronger than that at underwater conditions. Both polymer II and III exhibit a high bonding strength around 1.0 $\mathrm{MPa}$ (0.90 MPa for polymer II and 1.01 MPa for polymer III, respectively), which is also around two times stronger than that at underwater conditions. Polymer IV, on the other hand, shows an average bonding strength of $1.10 \mathrm{MPa}$, only slightly higher than that at underwater conditions (1.02 $\mathrm{MPa})$. With regard to the bonding strength on glass substrate, the average underwater bonding strength $(1.13 \mathrm{MPa})$ of polymer IV is even higher than that at dry conditions $(0.92 \mathrm{MPa})$. We can safely make the conclusion that polymer IV exhibits very strong underwater bonding strength comparable to that at dry conditions, whereas the other three polymers generally show much lower bonding strength at underwater conditions than at dry conditions. It is worthwhile to mention that although polymer III consists of all amide-bond-containing repeating units, which at the first glance is similar to the all lactam-bond containing repeating units of polymer IV (in terms of similar polarity of the amide and lactam bonds), it shows weaker underwater bonding strength than polymer IV, reflecting that the subtle change of the polar bonds may have great influence on underwater bonding.

It should be mentioned that the reliability of average bonding strength of four different polymers in all three (under seawater, under DI water and dry) conditions were tested by one-way ANOVA analysis, and the results were shown in Table S2. It showed that there is statistical difference $(P<0.05)$ between the average bonding strength in three test conditions for all the polymers. In ANOVA analysis, it is assumed that if there is no influence of polymer polarity on the adhesion strength, there should be no significant difference between the model mean square and error mean square. As can be seen from Table S2, 
a)

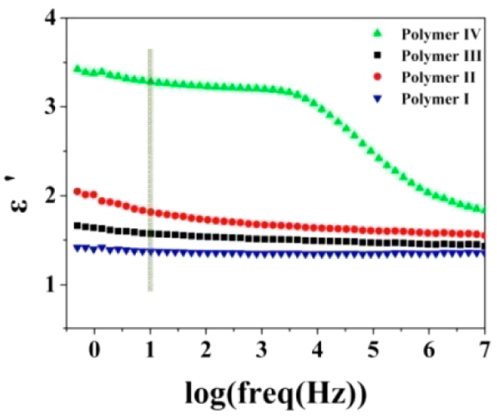

b)

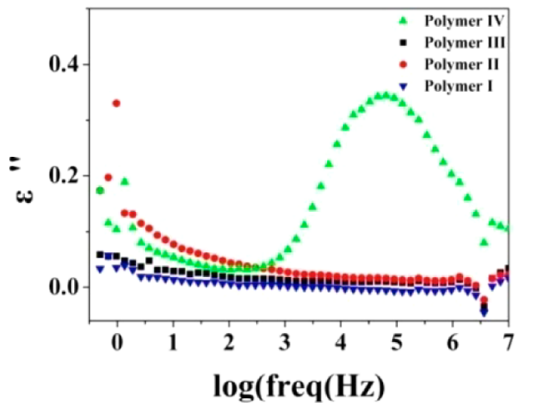

c)

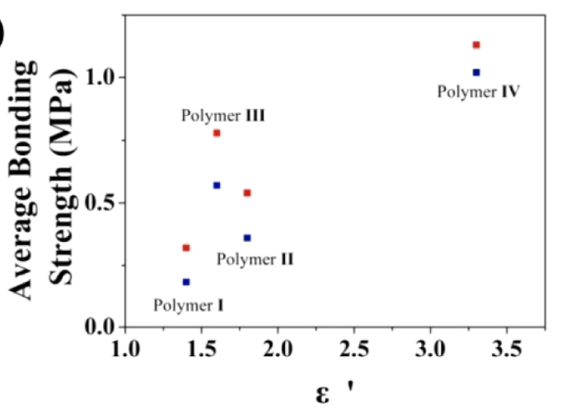

Figure 3. Variation in (a) real $\left(\varepsilon^{\prime}\right)$ part and (b) imaginary $\left(\varepsilon^{\prime \prime}\right)$ part of dielectric constant with frequency for polymer I-IV. (c) Interrelationship between average bonding strength (red square, on glass substrate; blue square:, on Al substrate) and dielectric constant for polymer I-IV.

the error mean square (in $1 \times 10^{-3}$ to $1 \times 10^{-2}$ range) is much less than the model mean square (close to 0.5 ), which means that polymer polarity is a notable factor. Also, $\mathrm{F}$ value is used to assess whether the expected values (bonding strength) of a quantitative variable (polarity) within the four predefined groups (four polymers) differ from each other. The $\mathrm{F}$ values calculated from all samples are significantly higher than 1 , which again supports that the polarity of the polymer does have effects on the bonding strength.

The underwater bonding strength increases with the increase of the amide/lactam bond content, which indicates that there might be a correlation between the polarity of the polymer and underwater bonding. The solubility of the four polymers in different solvent systems gives an intuitive estimation of the polarity of these adhesives, in the order of I $<$ II $<$ III $<$ IV; however, more solid proof is needed. Hence, the dielectric constant $(\varepsilon)$, which is directly correlated to the polarity of materials, ${ }^{31}$ is used to evaluate the polarity of the four polymers. Normally, $\varepsilon$ of a material could be determined by measuring the capacitance and resistance change of the material under AC sinusoidal voltage, which provides not only the real part of electric constant $\left(\varepsilon^{\prime}\right)$, but also the imaginary part $\varepsilon^{\prime \prime} .^{31}$ The dielectric constant of polymer I-IV were measured on a Novocontrol Alpha Dielectric Spectrum Tester at $25{ }^{\circ} \mathrm{C}$ and atmospheric pressure, in the frequency range from $1 \times 10^{-1} \mathrm{~Hz}$ to $1 \times 10^{7} \mathrm{~Hz}$. Samples of polymer I, III, and IV for tests were compressed plates $(1.0 \mathrm{~mm}$ in thickness and $10.0 \mathrm{~mm}$ in diameter) made from powders, whereas samples of polymer II are plates with the same size but made from the viscoelastic solid. The results are shown in Figure 3. For simplicity, $\varepsilon^{\prime}$ measured at $1 \times 10^{1} \mathrm{~Hz}$ could be considered as the real dielectric constant $\varepsilon^{*}$, because $\varepsilon^{\prime \prime}$ at this frequency is much smaller than $\varepsilon^{\prime}$. Polymer I exhibits the lowest $\varepsilon^{\prime}\left(1.4\right.$ at $1 \times 10^{1}$ $\mathrm{Hz}$, as shown in Figure 3a), and polymer IV exhibits the highest $\varepsilon^{\prime}\left(3.3\right.$ at $\left.1 \times 10^{1} \mathrm{~Hz}\right)$, whereas polymer II and III exhibit a dielectric constant in between, but much closer to the $\varepsilon^{\prime}$ value of polymer $\mathbf{I}$.
The much higher $\varepsilon^{\prime}$ value of polymer IV compared to other three polymers is very interesting, which might contribute to the high underwater bonding strength of polymer IV. We noticed a relaxation peak of dielectric loss $\varepsilon^{\prime \prime}$ of polymer IV appears at high frequency of $1 \times 10^{4}$ to $1 \times 10^{6} \mathrm{~Hz}$, and as a consequence, an obvious drop in $\varepsilon^{\prime}$ value is recorded, which makes the $\varepsilon^{\prime}$ value closer to that of polymer II and III. Such a dipole relaxation process is not observed for the other three polymers, as shown in Figure $3 \mathbf{b}$. These evidence indicate that there is a specific dipole moment related to the lactam containing repeating units, which does not exist in other three polymers. This dipole moment displays a relaxation process with the relaxation time $(\tau)$ of $2 \times 10^{-6} \mathrm{~s}$ approximately at room temperature, which contributes to the high $\varepsilon^{\prime}$ value of polymer IV at low frequencies.

However, the measured $\varepsilon$ values of polymers II and III are a little bit confusing, because polymer II exhibits a higher dielectric constant (1.8) than polymer III (1.6), which conflicts with the widely accepted knowledge that amide bond is more polar than ester bond and the fact that that polymer II could be dissolve in less polar acetone $\left(\varepsilon^{*} 20.7\right)$ but polymer III could only be dissolved in more polar solvents such as DMF $\left(\varepsilon^{*}\right.$ 38.3) and DMSO $\left(\varepsilon^{*} 47.2\right)$. We reasoned that such a deviation might be arisen from the deferent sample preparation methods. Polymer II, as depicted before, was obtained as a viscoelastic solid when precipitated out from the polymerization solution. This made its purification much more difficult than the other three polymers, which exist as powders that could be easily purified. May the existence of polar impurities (such as trace amount of polar solvent such as DMF that was used in polymerization) influence the final outcome of the dielectric constant tests. The overall trend though is as we expected, that is, the underwater bonding strength increases with the increase in polarity of the polymer, as shown in Figure 3c.

The measured dielectric constants reflect the contribution of the polar bonds in the repeating units to the polarity of the whole polymer, given that the contribution from catechol 

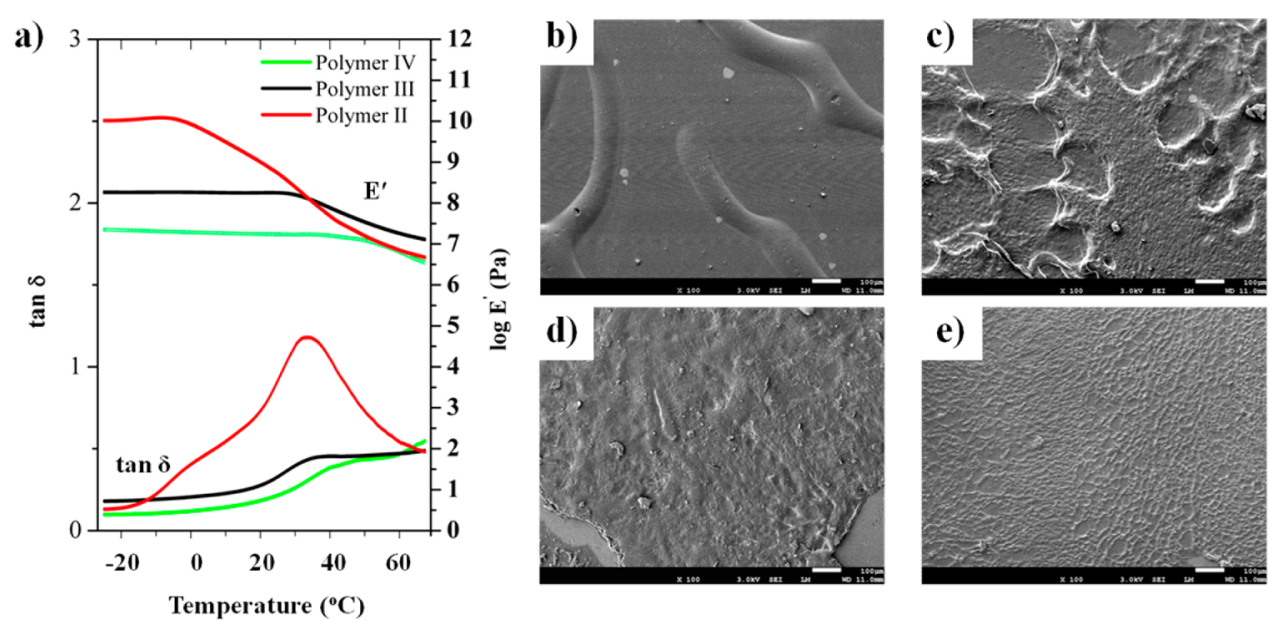

Figure 4. (a) Loss modulus $E^{\prime}$ and $\tan \delta$ curve in dynamic mechanical analysis (DMA) for polymer II, III, and IV and (b-e) SEM images of the adhesion sections of glass substrates after lap-shear test: (b) polymer I, (c) polymer II, (d) polymer III, and (e) polymer IV as the adhesive, respectively.

groups in four polymers is similar, since all four polymers have similar catechol contents. We speculate that the interfacial interaction of other functionalities in the polymers to surfaces also contributes to the realization of strong underwater bonding, since the polar-polar interactions and H-bonding between the those functional groups and the attached surface could not be ignored. Previous reports already verified that the higher polarity of polymer can lead to stronger $\mathrm{H}$-bonding. ${ }^{32}$ Very interestingly, the dielectric constant of glass and $\mathrm{Al}_{2} \mathrm{O}_{3}$ (the surface of $\mathrm{Al}$ is always covered by a layer of $\mathrm{Al}_{2} \mathrm{O}_{3}$ ) is around 3.8 and 4.5 , respectively, which matches quite well with the dielectric constant of polymer IV (3.3). We also test the bonding strength of the four polymers on PTFE, a substrate with a very low surface energy, and the results were shown in Figure S11. A similar trend was observed for underwater bonding on PTFE substrates, with an average bonding strength of $24.4 \mathrm{KPa}$ for polymer IV, which is very high for a lowsurface-energy substrate.

To further evaluate the contribution of the polymer backbone in underwater adhesion, we conducted dynamic mechanical analysis (DMA) tests. Unfortunately, polymer I with polystyrene backbone was too brittle to obtain a film suitable for DMA test, so only the results from the other three polymers were compared, as shown in Figure 4a. Polymer IV shows the lowest loss modulus $E^{\prime}$, indicating that the interaction of polymeric backbone (such as polar-polar interaction and $\mathrm{H}$-bonding) of polymer IV was stronger that polymers II and III, which is in accordance with the higher cohesion when being used as the adhesive. Meanwhile, polymer IV exhibited the highest glass-transition temperature $\left(T_{\mathrm{g}}\right)$, as shown by the $\tan \delta-T$ curves, presumably due to the stronger interchain interactions existed between the polymer chains. Furthermore, $\tan \delta-T$ curves also provides useful information about the inter energy dissipation inside the polymers. With the increase in amide bond contents from polymer II (20 mol \%) to polymer III and IV (100 mol \%), the peak value of $\tan \delta$ decreased, whereas polymer IV showed the lowest value. This result indicates that with the increase in the polarity of the polymer, the interaction between the polymers chains became stronger, which made the movement of the chain segment more difficult. On the other hand, the loss modulus $E^{\prime}$ at room temperature of the polymers decreases in the order of polymer
II > polymer III > polymer IV. The lower loss modulus $E^{\prime}$, reflects the higher cohesive force existed in the adhesive.

We also did the SEM tests on the adhesion section of glass substrate after lap-shear test, as shown in Figure 4b-e. SEM results displayed the status of the cross-linked adhesive on the substrate after pulling-off. PVP adhesive formed a much more compact film (Figure 4e) on the glass, indicating that with the increase in polarity, the cross-linked adhesive film became more compact.

\section{CONCLUSIONS}

In summary, four mussel-inspired adhesives with similar catechol contents and molecular weights but different polymer backbones were synthesized and their underwater adhesion properties were compared. It was disclosed that besides the critical role of catechol moiety, the polarity of the polymer backbone might also contribute to the realization of strong underwater adhesion. It was found that the underwater bonding strength increases with the increase in the amide/lactam bond content on the backbone. Dielectric constant was introduced to evaluate the polarity of the mussel-inspired adhesives, which provides a semiquantitative parameter to correlates the contribution of polymer polarity to the underwater bonding properties. Polymer IV with the PVP backbone, with the highest $\varepsilon^{\prime}$ value (3.3), exhibits the best underwater adhesion behavior, the underwater bonding strength of which exceeds 1.0 $\mathrm{MPa}$, five times stronger than that of polymer $\mathbf{I}$ with polystyrene backbone. DMA results also indicate that with the increase of the polarity of the polymers, the interaction between the polymer chains becomes stronger, which leads to smaller loss modulus $\mathrm{E}^{\prime}$, smaller peak value of $\tan \delta$, and higher $T_{\mathrm{g}}$, and contributes to the improved underwater bonding strength. Although other factors, such as hydrophilic/hydrophobic balance, synergic effect of amino groups are still needed to be considered, our results indicate that the polarity of the polymer backbone is a factor that might be added to the consideration sheets for the design of more effective musselinspired underwater adhesives. While we are preparing this article, we noticed Wilker and co-workers just boosted the underwater bonding strength of polystyrene based adhesive to 3.0 $\mathrm{MPa}$ by increasing its molecular weight to $80 \mathrm{kDa} .{ }^{33} \mathrm{We}$ anticipate that if the molecular weight of the adhesive based on 
PVP backbone could be increased to a similar level, a much higher underwater bonding strength would be possible. Currently, the molecular weight of polymer IV is limited by its preparation method, and we are working on the synthetic methodology to prepare PVP-based mussel-inspired adhesives with higher molecular weight for better underwater performance.

\section{ASSOCIATED CONTENT}

\section{S Supporting Information}

The Supporting Information is available free of charge on the ACS Publications website at DOI: 10.1021/acsbiomaterials. 7 b00673.

General information for materials and instruments; polymer synthesis procedure; ${ }^{1} \mathrm{H}$ NMR spectra for all polymers; supplemental underwater bonding tests data; ANOVA analysis data (PDF)

\section{AUTHOR INFORMATION}

\section{Corresponding Author}

*E-mail: wanxb@qibebt.ac.cn.

\section{ORCID}

Xiaobo Wan: 0000-0001-5740-512X

\section{Author Contributions}

${ }^{\dagger}$ Y.M. and X.W. contributed equally.

\section{Notes}

The authors declare no competing financial interest.

\section{ACKNOWLEDGMENTS}

This work was supported by the National Science Foundation of China (51603223) and the Shandong Provincial Natural Science Foundation of China (ZR2015EQ008).

\section{REFERENCES}

(1) Yu, J.; Kan, Y.; Rapp, M.; Danner, E.; Wei, W.; Das, S.; Miller, D. R.; Chen, Y.; Waite, J. H.; Israelachvili, J. N. Adaptive Hydrophobic and Hydrophilic Interactions of Mussel Foot Proteins with Organic Thin Films. Proc. Natl. Acad. Sci. U. S. A. 2013, 110, 15680-15685.

(2) Seo, S.; Das, S.; Zalicki, P. J.; Mirshafian, R.; Eisenbach, C. D.; Israelachvili, J. N.; Waite, J. H.; Ahn, B. K. Microphase Behavior and Enhanced Wet-Cohesion of Synthetic Copolyampholytes Inspired by a Mussel Foot Protein. J. Am. Chem. Soc. 2015, 137, 9214-9217.

(3) Maier, G. P.; Rapp, M. V.; Waite, J. H.; Israelachvili, J. N.; Butler, A. Adaptive Synergy Between Catechol and Lysine Promotes Wet Adhesion by Surface Salt Displacement. Science 2015, 349, 628-632.

(4) Wei, W.; Yu, J.; Broomell, C.; Israelachvili, J. N.; Waite, J. H.Hydrophobic Enhancement of Dopa-Mediated Adhesion in a Mussel Foot Protein. J. Am. Chem. Soc. 2013, 135, 377-383.

(5) Li, L.; Smitthipong, W.; Zeng, H. Mussel-inspired Hydrogels for Biomedical and Environmental Applications. Polym. Chem. 2015, 6 (3), 353-358.

(6) Waite, J. H.; Tanzer, M. L. Polyphenolic Substance ofMytilus edulis: Novel Adhesive Containing L-Dopa and Hydroxyproline. Science 1981, 212, 1038-1040.

(7) Silverman, H. G.; Roberto, F. F. Understanding Marine Mussel Adhesion. Mar. Biotechnol. 2007, 9, 661-681.

(8) Xu, Z. Mechanics of Metal-Catecholate Complexes: The Roles of Coordination State and Metal Types. Sci. Rep. 2013, 3, 2914-2910.

(9) Yang, J.; Cohen Stuart, M. A.; Kamperman, M. Jack of All Trades: Versatile Catechol Crosslinking Mechanisms. Chem. Soc. Rev. 2014, 43, 8271-8298.

(10) Sedo, J.; Saiz-Poseu, J.; Busque, F.; Ruiz-Molina, D. CatecholBased Biomimetic Functional Materials. Adv. Mater. 2013, 25, 653701.
(11) Ryu, J. H.; Lee, Y.; Kong, W. H.; Kim, T. G.; Park, T. G.; Lee, H. Catechol-Functionalized Chitosan/Pluronic Hydrogels for Tissue Adhesives and Hemostatic Materials. Biomacromolecules 2011, 12, 2653-2659.

(12) Zhou, J.; Bhagat, V.; Becker, M. L. Poly(ester urea)-Based Adhesives: Improved Deployment and Adhesion by Incorporation of Poly(propylene glycol) Segments. ACS Appl. Mater. Interfaces 2016, 8, 33423-33429.

(13) Lee, H.; Lee, B. P.; Messersmith, P. B. A Reversible Wet/Dry Adhesive Inspired by Mussels and Geckos. Nature 2007, 448, 338341.

(14) Glass, P.; Chung, H.; Washburn, N. R.; Sitti, M. Enhanced Reversible Adhesion of Dopamine Methacrylamide-Coated ElastomerMicrofibrillar Structures Under Wet Conditions. Langmuir 2009, $25,6607-6612$.

(15) Stepuk, A.; Halter, J. G.; Schaetz, A.; Grass, R. N.; Stark, W. J. Mussel-Inspired Load Bearing Metal-Polymer Glues. Chem. Commun. 2012, 48, 6238-6240.

(16) Shao, H.; Stewart, R. J. Biomimetic Underwater Adhesives with Environmentally Triggered Setting Mechanisms. Adv. Mater. 2010, 22, 729-733.

(17) Stewart, R. J.; Wang, C. S.; Shao, H. Complex Coacervates as a Foundation for Synthetic Underwater Adhesives. Adv. Colloid Interface Sci. 2011, 167, 85-93.

(18) White, J. D.; Wilker, J. J. Underwater Bonding with Charged Polymer Mimics of Marine Mussel Adhesive Proteins. Macromolecules 2011, 44, 5085-5088.

(19) Matos-Perez, C. R.; White, J. D.; Wilker, J. J. Polymer Composition and Substrate Influences on the Adhesive Bonding of a Biomimetic, Cross-Linking Polymer. J. Am. Chem. Soc. 2012, 134, 9498-9505.

(20) Meredith, H. J.; Jenkins, C. L.; Wilker, J. J.Enhancing the Adhesion of a Biomimetic Polymer Yields Performance Rivaling Commercial Glues. Adv. Funct. Mater. 2014, 24, 3259-3267.

(21) Mu, Y.; Wan, X. Simple but Strong: A Mussel-Inspired Hot Curing Adhesive Based on Polyvinyl Alcohol Backbone. Macromol. Rapid Commun. 2016, 37, 545-550.

(22) Westwood, G.; Horton, T. N.; Wilker, J. J. Simplified Polymer Mimics of Cross-Linking Adhesive Proteins. Macromolecules 2007, 40, 3960-3964

(23) Zhang, H.; Bre, L.; Zhao, T.; Newland, B.; Wang, W. Biomimetic Hyperbranched Poly(amino ester)-BasedNanocomposite as Tunable Bone Adhesive for Sternal Closure. J. Mater. Chem. B 2014, 2, 4067-4071.

(24) Jia, M.; Li, A.; Mu, Y.; Jiang, W.; Wan, X. Synthesis and Adhesive Property Study of Polyoxetanes Grafted with Catechols via $\mathrm{Cu}$ (I)-Catalyzed Click Chemistry. Polymer 2014, 55, 1160-1166.

(25) Li, A.; Mu, Y.; Jiang, W.; Wan, X. A Mussel-Inspired Adhesive with Stronger Bonding Strength Under Underwater Conditions Than Under Dry Condition. Chem. Commun. 2015, 51, 9117-9120.

(26) Waite, J. H. Adhesion à la Moule. Integr. Comp. Biol. 2002, 42, $1172-1180$

(27) Wilke, P.; Helfricht, N.; Mark, A.; Papastavrou, G.; Faivre, D.; Borner, H. G. A Direct Biocombinatorial Strategy Toward Next Generation, Mussel-Glue Inspired Saltwater Adhesives. J. Am. Chem. Soc. 2014, 136, 12667-12674.

(28) Shafiq, Z.; Cui, J.; Pastor-Perez, L.; San Miguel, V.; Gropeanu, R. A.; Serrano, C.; del Campo, A. Bioinspired Underwater Bonding and Debonding on Demand. Angew. Chem., Int. Ed. 2012, 51, 43324335.

(29) Wei, W.; Petrone, L.; Tan, Y.; Cai, H.; Israelachvili, J. N.; Miserez, A.; Waite, J. H. An Underwater Surface-Drying Peptide Inspired by a Mussel Adhesive Protein. Adv. Funct. Mater. 2016, 26, 3496-3507.

(30) Zhao, Q.; Lee, D.; Ahn, B. K.; Seo, S.; Kaufman, Y.; Israelachvili, J. N.; Waite, J. H. Underwater Contact Adhesion and Microarchitecture in Polyelectrolyte Complexes Actuated by Solvent Exchange. Nat. Mater. 2016, 15, 407-412. 
(31) Szotek, S.; Czogała, J.; Ścigała, K.; Marycz, K.; Maksymowicz, K. Dielectric and Electrical Properties of Solids, in: Micro- and MacroProperties of Solids; Springer: Berlin, 2006, pp199-255.

(32) Gur'yanova, E. N.; Gol'dshtein, I. P.; Perepelkova, T. I. The Polarity and Strength of the Intermolecular Hydrogen Bond. Russ. Chem. Rev. 1976, 45, 792-806.

(33) North, M. A.; Del Grosso, C. A.; Wilker, J. J. High Strength Underwater Bonding with Polymer Mimics of Mussel Adhesive

Proteins. ACS Appl. Mater. Interfaces 2017, 9, 7866-7872. 